\title{
Ensino de radiação térmica associada ao efeito estufa na perspectiva da teoria dos campos conceituais de Vergnaud
}

\author{
Daniele Leandro Martins ${ }^{1}$, Fábio Alencar dos Santos ${ }^{2}$ \\ 1, 2 Universidade Federal da Grande Dourados (UFGD)
}

Palavras-Chave: Radiação Térmica, Efeito Estufa, Teoria dos Campos Conceituais.

\section{Introdução}

É sabido que diversas pesquisas vêm sendo desenvolvidas a procura de novas metodologias e materiais didáticos para inserção da Física Moderna e Contemporânea (FMC) no Ensino Médio (EM). A FMC chama a atenção da humanidade desde seus primórdios, e um grande desafio para os estudiosos da área, bem como, para profissionais da educação tem sido a transmissão do conhecimento científico de maneira mais simplificada. É interessante mostrar que conceitos e equações da FMC estão conectados integral ou parcialmente com acontecimentos cotidianos, e aparatos tecnológicos utilizados pela sociedade moderna, permitindo acima de tudo a formação de estudantes mais reflexivos, investigadores. Neste contexto, o objetivo deste trabalho foi introduzir a FMC em uma escola de EM através dos conceitos de radiação térmica ancorado na experimentação, via associação com o efeito estufa, e discutida na perspectiva da Teoria dos Campos Conceituais (TCC) de Vergnaud.

A TCC amplia e direciona a teoria de Piaget com foco nas operações lógicas, das estruturas gerais do pensamento para aquisição do conhecimento cognitivo baseado no sujeito em situação (Moreira, 2002). Para Vergnaud (1996) "no momento em que nos interessamos por aquilo que se passa na sala de aula, somos obrigados a nos interessar especialmente pelo conteúdo do conhecimento". Pensando nisso a maior dificuldade do ensino é obter um avanço do conceito implícito para o conceito explícito, do saber fazer para o saber explicitar. Vergnaud argumenta que é aceitável que o aluno não domine o campo conceitual em um curto prazo, já que o conhecimento organizado em campos conceituais leva um período maior de tempo para ser compreendido pelo aluno e requer experiência, maturidade e aprendizagem (VIEIRA; BAZZO, 2007). Os conceitoschave da teoria dos campos conceituais além do próprio conceitos de campo conceitual, são os conceitos de esquema, situação, invariante operatório e a sua concepção de conceito (Moreira, 2002). Nessa perspectiva fundamentou-se a abordagem de ensino com proposições fundamentais para efetivação da aplicação do produto.

\section{Metodologia e material}

Preparamos uma sequência didática (SD) baseada em um aparato experimental construído com materiais de baixo custo, coleta de dados, simulação e textos didáticos. A SD foi aplicada em dois momentos de 100 minutos para uma turma de 19 alunos do $2^{\circ}$ ano matutino do EM da Escola Estadual Marechal Rondon em Mundo Novo - MS. No primeiro momento aplicamos o questionário pré-teste para verificar os conhecimentos prévios dos alunos, em seguida, houve uma discussão sobre a temática Radiação Térmica associada ao Efeito Estufa, manuseio do aparato, coleta de dados pelos alunos, leitura de textos informativos extraídos da internet e do livro didático do aluno. No segundo momento as aulas foram ministradas no laboratório de informática da escola, para utilização dos recursos midiáticos.

Com aula expositiva e dialogada, iniciou-se a apresentação de slides com revisão do conteúdo espectro eletromagnético, apresentação e discussão da planilha com os dados coletados do aparato, e simulação computacional sobre radiação de corpo negro no PhET - Interactive Simulations, Blackbody Spectrum para comparação com a lâmpada incandescente usada no experimento. A eficácia da SD foi validada por meio da aplicação do questionário pós-teste, o mesmo aplicado no início desta SD, com objetivo de verificar se houve mudança conceitual na compreensão dos conceitos de radiação térmica. 


\section{Resultados e Discussão}

A eficácia da SD foi avaliada por comparação das repostas aos questionários pré- e pós-teste, que verificaram conhecimentos prévios dos alunos, e ao final da SD validaram se houve mudança conceitual. Os resultados foram avaliados em dois blocos de questões, sendo as quatro primeiras sobre o efeito estufa (bloco 1 ) e as três seguintes sobre radiação térmica (bloco 2). Com relação as respostas contidas no bloco 1, comparando os questionários pré- e pós teste, percebemos que a interpretação dos alunos foi bastante parecida. No questionário pré-teste referente a questão 1 que procurou verificar sobre o conhecimento do efeito estufa, $84,21 \%$ dos alunos responderam conhecer o fenômeno através de jornais e informações da internet, e em suas justificativas a maioria das respostas relacionaram com o aquecimento global, temperatura da Terra e a poluição, mostrando a influência da mídia nas justificativas como um fenômeno trágico, incontestável e supostamente aceito como científico. No pós teste após o desenvolvimento da sequência didática a questão 1 aumentou o percentual para $100 \%$ de conhecimento sobre o fenômeno, porém, as justificativas não apresentaram domínio sobre o campo conceitual do efeito estufa. Para Vergnaud é aceitável que o aluno não domine o campo conceitual em um curto prazo, já que o conhecimento organizado em campos conceituais leva um período maior de tempo para ser compreendido pelo aluno e requer experiência, maturidade e aprendizagem (VIEIRA; BAZZO, 2007).

No Bloco 2 procurou-se identificar o conhecimento dos alunos nas situações cotidianas e fenômenos naturais em que ocorrem o processo de propagação de calor. Na comparação quantitativa do pré- e pós-teste para pergunta 6 verificamos um aumento de aproximadamente $11 \%$ para alternativa verdadeira após aplicação do produto educacional, tal resultado sugere um possível avanço no entendimento do conceito de radiação térmica e suas fontes. Analisando as justificativas percebemos uma boa expectativa quanto a construção do conhecimento do teorema-em-ação (radiação térmica) com escritas simplificadas e termos científicos. Por outro lado, alguns alunos apresentaram justificativas que podem ter surgido de discussões durante aplicação da sequência didática destacando que não houve evolução conceitual. Uma vez que não conseguimos verificar uma evolução conceitual para todos os alunos, apesar do aumento quantitativo, avaliamos que talvez seja necessária uma reaplicação do produto, com abordagem diferente da primeira aplicação, especialmente no que e refere a construção dos conceitos envolvidos, para assim atingir mais indivíduos e realmente ampliar o conhecimento conceitual.

\section{Conclusões}

Tendo em vista conteúdo específico do conhecimento, e a verificação do domínio conceitual, podemos dizer que a aplicação do produto/sequência didática obteve resultados satisfatórios em relação aos conceitos físicos envolvidos. Verificamos que é necessário um olhar diferenciado para o processo ensino-aprendizagem desse campo conceitual, e destacamos que a experimentação aplicada e a análise da relação dos conceitos com o cotidiano do aluno foram fundamentais para desmistificar conceitos prévios e fortalecer o conhecimento científico.

\section{Referências}

MOREIRA, M. A. A. teoria dos campos conceituais de Vergnaud, o ensino de ciências e a pesquisa nesta área. Investigações em ensino de ciências, V. 7, n. 1, p. 7-29, 2002.

VERGNAUD, G. A trama dos campos conceituais na construção dos conhecimentos. Revista do GEMPA, N. 4, P. 9-19, 1996.

VIEIRA, K. R. C. F; BAZZO, W. A. Discussões acerca do aquecimento global: uma proposta CTS para abordar esse tema controverso em sala de aula. Ciência \& Ensino, v. 1, p. 1-12, 2007. 